University of Nebraska - Lincoln

DigitalCommons@University of Nebraska - Lincoln

$12-15-2005$

\title{
Magnetic and spectroscopic characteristics of ZnMnO system
}

\author{
Aswini K. Pradhan \\ Center for Materials Research, Norfolk State University, apradhan@nsu.edu \\ D. Hunter \\ Norfolk State University, Norfolk, VA
}

Kai Zhang

Norfolk State University, Norfolk, VA

J.B. Dadson

Norfolk State University, Norfolk, VA

S. Mohanty

Norfolk State University, Norfolk, VA

See next page for additional authors

Follow this and additional works at: https://digitalcommons.unl.edu/physicssellmyer

Part of the Physics Commons

Pradhan, Aswini K.; Hunter, D.; Zhang, Kai; Dadson, J.B.; Mohanty, S.; Williams, T.M.; Lord, K.; Rakimhov, R.R.; Roy, U.N.; Cui, Y.; Burger, A.; Zhang, Jun; and Sellmyer, David J., "Magnetic and spectroscopic characteristics of ZnMnO system" (2005). David Sellmyer Publications. 191.

https://digitalcommons.unl.edu/physicssellmyer/191

This Article is brought to you for free and open access by the Research Papers in Physics and Astronomy at DigitalCommons@University of Nebraska - Lincoln. It has been accepted for inclusion in David Sellmyer Publications by an authorized administrator of DigitalCommons@University of Nebraska - Lincoln. 


\section{Authors}

Aswini K. Pradhan, D. Hunter, Kai Zhang, J.B. Dadson, S. Mohanty, T.M. Williams, K. Lord, R.R. Rakimhov, U.N. Roy, Y. Cui, A. Burger, Jun Zhang, and David J. Sellmyer 
Published in Applied Surface Science, 252:5 (15 December 2005), pp. 1628-1633. Copyright (C 2005 Elsevier B.V. Used by permission. http://www.springerlink.com/content/1573-1839/

\title{
Magnetic and spectroscopic characteristics of ZnMnO system
}

\author{
A.K. Pradhan ${ }^{\mathrm{a},}$, D. Hunter ${ }^{\mathrm{a}}$, Kai Zhang ${ }^{\mathrm{a}}$, J.B. Dadson ${ }^{\mathrm{a}}$, S. Mohanty ${ }^{\mathrm{a}}$, \\ T.M. Williams ${ }^{\mathrm{a}}$, K. Lord ${ }^{\mathrm{a}}$, R.R. Rakhimov ${ }^{\mathrm{a}}$, U.N. Roy ${ }^{\mathrm{b}}, \mathrm{Y}$. Cui ${ }^{\mathrm{b}}$, A. Burger ${ }^{\mathrm{b}}$, \\ Jun Zhang ${ }^{\mathrm{c}}$ and D.J. Sellmyer ${ }^{\mathrm{c}}$ \\ ${ }^{a}$ Center for Materials Research, Norfolk State University, 700 Park Avenue, Norfolk, VA 23504, USA \\ bDepartment of Physics, Fisk University, 1000, 17 Avenue North, Nashville, TN 37208, USA \\ cDepartment of Physics and Astronomy and Center for Materials Research and Analysis \\ University of Nebraska-Lincoln, Lincoln, NE 68588-0113, USA
}

Submitted January 2005; revised February 2005; accepted February 2005; available online 10 May 2005.

\begin{abstract}
We report on the observation of room-temperature ferromagnetism in epitaxial $(\mathrm{Zn}, \mathrm{Mn}) \mathrm{O}$ films grown by a pulsed-laser deposition technique using high-density targets. The X-ray, microscopic, spectroscopic and magnetic properties of target material containing 6 at. $\%$ of $\mathrm{Mn}$ and films were compared. The target shows the presence of large clusters exhibiting paramagnetic behavior. However, ferromagnetic properties were observed in ( $\mathrm{Zn}, \mathrm{Mn}) \mathrm{O}$ films grown at a substrate temperature of $500{ }^{\circ} \mathrm{C}$ and with an oxygen partial pressure of $1 \mathrm{mTorr}$. Although, crystalline quality of the film improves with increasing substrate temperature, the ferromagnetism becomes weaker.
\end{abstract}

The observation of ferromagnetic transition in (III, Mn)-V semiconductors [1], [2], [3], [4] and [5], such as GaMnAs, at higher temperatures (having Curie temperature $>100 \mathrm{~K}$ ) has attracted a lot of attention recently. The possibility of manipulating both charge and spin of electrons in semiconductors, its impact on information storage technology using ferromagnetic metals, and the recent demonstration of long spin-coherence time [6] have heightened research activities in dilute magnetic semiconductors
(DMS), including DMS oxides [7]. Following the theoretical prediction [8] that transition metals, especially $\mathrm{Mn}$, doped with $\mathrm{GaN}$ and $\mathrm{ZnO}$ could show large ferromagnetic Curie temperature, numerous studies have been carried out on $(\mathrm{Zn}, \mathrm{Mn}) \mathrm{O}$ and $(\mathrm{Ga}, \mathrm{Mn}) \mathrm{N}$ systems. The recent discovery of ferromagnetism [4] and [9] in $(\mathrm{Ga}, \mathrm{Mn}) \mathrm{N}$ at temperatures much higher than the room temperature has initiated research interest that these materials can indeed have profound technological impact. 
Recently, ferromagnetism in bulk, nanostructures and $\mathrm{Mn}$ ion-implanted $\mathrm{ZnO}$ films has been observed [10], [11], [12] and [13]. The reported ferromagnetic transition temperature varies from 50 to $300 \mathrm{~K}$. On the other hand, $\mathrm{ZnMnO}$ films prepared by magnetron sputtering [14], pulsed laser deposition [15] and polycrystalline samples [16] did not show ferromagnetic behavior. Recently, ferromagnetism has been reported [17] in both $\mathrm{ZnMnO}$ bulk and thin film with ferromagnetic Curie temperature $T_{\mathrm{c}}>420 \mathrm{~K}$. This has aroused intense interest in this wide band gap semiconductor for possible spintronic applications. There are large controversies and difference in results in this system, which is attributed to the difference in preparation techniques. Apart from this, the metastable behavior of ferromagnetism, which not related to the carrier-mediated phenomenon [18], raised the questions on real origin of ferromagnetism in $\mathrm{ZnMnO}$ system. In this paper, we demonstrate the observation of roomtemperature ferromagnetism in epitaxial $(\mathrm{Zn}, \mathrm{Mn}) \mathrm{O}$ films grown by a pulsed-laser deposition technique using high-density targets. However, the target containing 6 at.\% of $\mathrm{Mn}$ shows the presence of large clusters exhibiting paramagnetic behavior. The ferromagnetic properties were observed in $(\mathrm{Zn}, \mathrm{Mn}) \mathrm{O}$ films grown at an optimum substrate temperature of $500{ }^{\circ} \mathrm{C}$ and with an oxygen partial pressure of 1 mTorr. The ferromagnetism becomes weaker for films grown at higher substrate temperature despite higher crystalline quality of the film.

The $\mathrm{Zn}_{1-x} \mathrm{Mn}_{x} \mathrm{O} \quad(x=0.01-0.07)$ precursors were prepared by mixing $\mathrm{ZnO}$ and $\mathrm{MnO}_{2}$ (purity $99.999 \%$ ) powders stoichiometrically and calcined at $400^{\circ} \mathrm{C}$ for $8 \mathrm{~h}$. The calcined powders were ground, palletized and isostatically pressed at $400 \mathrm{MPa}$ in order to get a highly dense target. The target was sintered in air at $500{ }^{\circ} \mathrm{C}$ for $12-$ 20 h. ZnMnO/Sapphire $\left(\begin{array}{llll}0 & 0 & 0 & 1\end{array}\right)$ epitaxial films were grown by the pulsed-laser deposition (PLD) technique $(\mathrm{KrF}$ excimer, $\lambda=248 \mathrm{~nm}$, laser repetition rate of $5 \mathrm{~Hz}$ ) with a pulse energy density of $1-$ $2 \mathrm{~J} / \mathrm{cm}^{2}$ and utilizing both target and substrate rotation facilities. High-density $\mathrm{Zn}_{0.94} \mathrm{Mn}_{0.06} \mathrm{O}$ target was used. The films were deposited with a substrate temperature $T_{\mathrm{s}}=500-600{ }^{\circ} \mathrm{C}$, keeping oxygen partial pressure $P_{\mathrm{O} 2}^{\mathrm{s}}=0.1-10$ mTorr. Clean single crystalline sapphire substrates were loaded to the chamber and heated just after the ultimate base pressure $<4 \times 10^{-8}$ Torr is reached. Phase identification was performed by the X-ray powder diffraction (XRD) method on a Rigaku X-ray diffractometer (XRD) using $\mathrm{Cu} \mathrm{K} \alpha$ radiation. The Raman spectra were recorded using Infinity LabRam micro-Raman spectrometer built around an Olympus Microscope BH2 and with $\mathrm{He}-\mathrm{Ne}$ laser excitation (wavelength: $632.8 \mathrm{~nm}$ ). The magnetization was measured using Quantum Design Superconducting Quantum Interference Device (SQUID-MPMS). The EPR experiments were done in an EMX Bruker spectrometer.

Fig. 1 shows the XRD patterns of $\mathrm{ZnMnO}$ bulk and thin film samples. The main XRD peaks for the bulk can be indexed to a hexagonal wurtzite $\mathrm{ZnO}$ structure. The XRD lines for $\mathrm{ZnMnO}$ bulk did not show any significant shifts compared to $\mathrm{ZnO}$. Three prominent additional lines are seen for $\mathrm{ZnMnO}$ bulk.

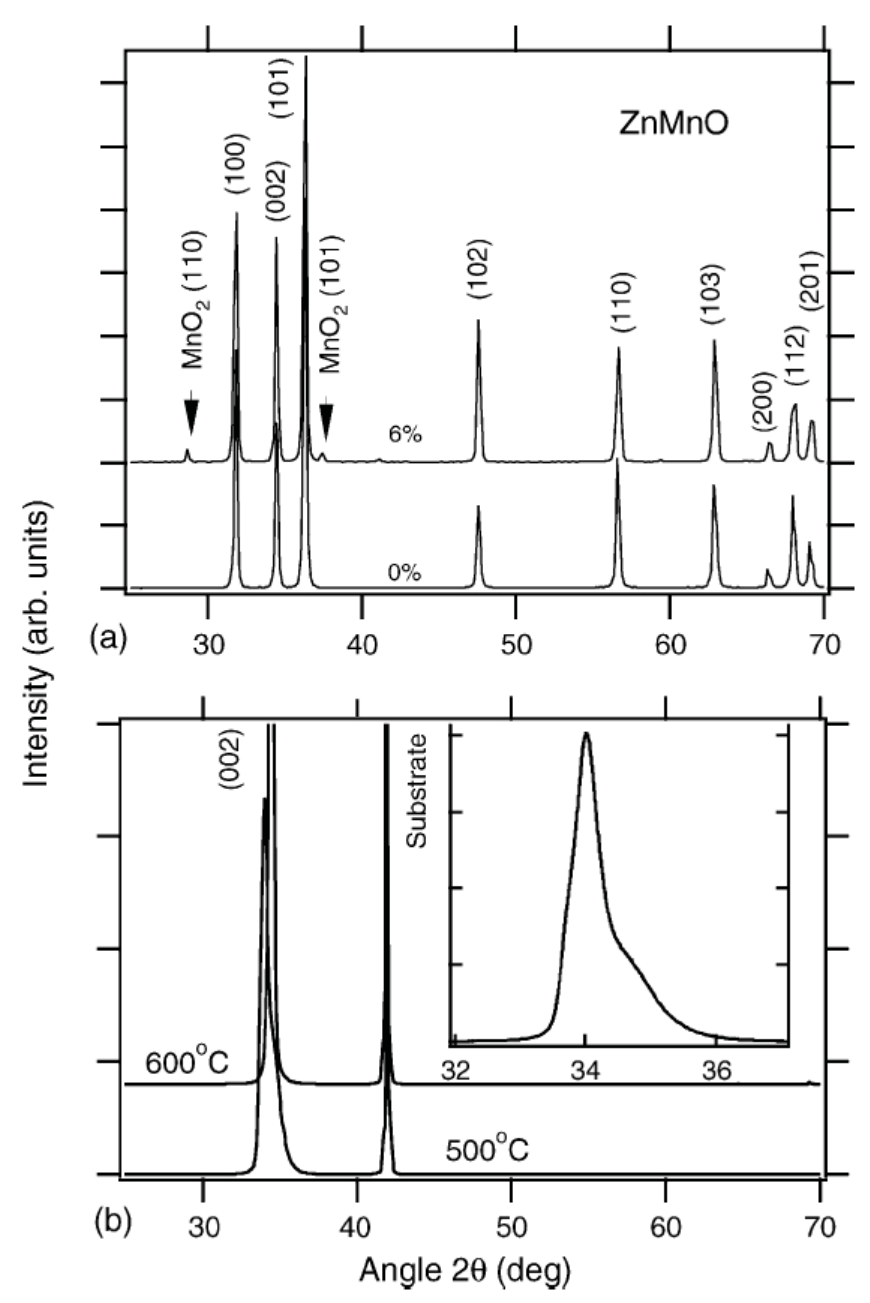

Fig. 1. X-ray diffraction pattern of $\mathrm{ZnMnO}$ (a) bulk with $\mathrm{Mn}=0$ and 6 at.\%, (b) film deposited at the substrate temperature of 500 and $600{ }^{\circ} \mathrm{C}$. The inset in (b) shows the rocking curve for the film grown at a substrate temperature of $500^{\circ} \mathrm{C}$. 
These peaks are arising from $\mathrm{MnO}_{2}$ and can be indexed as shown in Fig. 1. The indexing corresponds to synthetic $\mathrm{MnO}_{2}$ (pyrolusite), which is very stable with tetragonal rutile structure. It is also noted that similar XRD lines arise when the annealing temperature is increased for the lower concentration of $\mathrm{Mn}$ (not shown here). On the contrary, the XRD patterns of $\mathrm{ZnMnO} / \mathrm{Sapphire}\left(\begin{array}{llll}0 & 0 & 0 & 1\end{array}\right)$ films with a substrate temperature $T_{\mathrm{s}}=500$ and $600{ }^{\circ} \mathrm{C}$ reveal only one strong orientation ( 002 ), illustrating the epitaxial nature of the film. The rocking curve for the epitaxial growth of the film is shown in the inset of Fig. 1. The full-width half-maxima (FWHM) calculated from X-ray $\left(\begin{array}{lll}0 & 0 & 2\end{array}\right)$ line broadening shows that FWHM is $0.4^{\circ}$. It is noted that the FWHM decreases from 0.4 to $0.19^{\circ}$ with increasing $T_{\mathrm{s}}$ from 500 to $600{ }^{\circ} \mathrm{C}$ at an oxygen partial pressure $\left(\stackrel{\mathrm{S}}{\mathrm{O} 2}_{\mathrm{C}}\right)$ of $1 \mathrm{mTorr}$, illustrating the higher crystalline quality of the film grown at higher temperature. The XRD pattern also show that the $\left(\begin{array}{lll}0 & 0 & 2\end{array}\right)$ peak of film for $T_{\mathrm{s}}=500{ }^{\circ} \mathrm{C}$ shifts to lower angle compared to that of films grown at $T_{\mathrm{s}}=600{ }^{\circ} \mathrm{C}$. This clearly shows that $\mathrm{Mn}$ is incorporated into $\mathrm{Zn}$ lattice when films are synthesized at low $T_{\mathrm{s}}$ value. However, it is not clear yet that the broad peak observed at $T_{\mathrm{s}}=500{ }^{\circ} \mathrm{C}$ as shown in the inset of Fig. 1 is the phenomenon of phase segregation due to $\mathrm{ZnO}\left(\begin{array}{lll}0 & 0 & 2\end{array}\right)$ and $\mathrm{MnO}$ related phases. However, there is a possibility that the XRD peak broadening in films may be due the consequence of overlapping of two separate peaks arising from $\mathrm{ZnO}$ and $\mathrm{MnZnO}$ minority phase, whose presence is recently argued [19]. More studies are underway to explore this fact.

The scanning electron microscopic image (SEM) of the target surface is shown in Fig. 2(a). The SEM image shows that the larger clusters (bright spots) are embedded in the matrix, despite $12 \mathrm{~h}$ annealing at $500{ }^{\circ} \mathrm{C}$. The atomic force microscopy (AFM) images of as-grown $\mathrm{ZnMnO}$ films are shown in Fig. 2(b) and (c). The remarkable improvement of the crystalline quality and surface morphology is very clear with the increasing $T_{\mathrm{s}}$. The crystalline perfection of the surface is very consistent with the XRD results. The grain size increases from about 25$35 \mathrm{~nm}$ with increasing $T_{\mathrm{s}}$ from 500 to $600{ }^{\circ} \mathrm{C}$, resulting in high-quality epitaxial film grown at higher $T_{\mathrm{s}}$. The grains become very uniform and even coalesce in films grown at higher temperature.

In Fig. 3, we show the Raman spectra of $\mathrm{ZnMnO}$ for the target and films. $\mathrm{ZnO}$ belongs to the wurzite
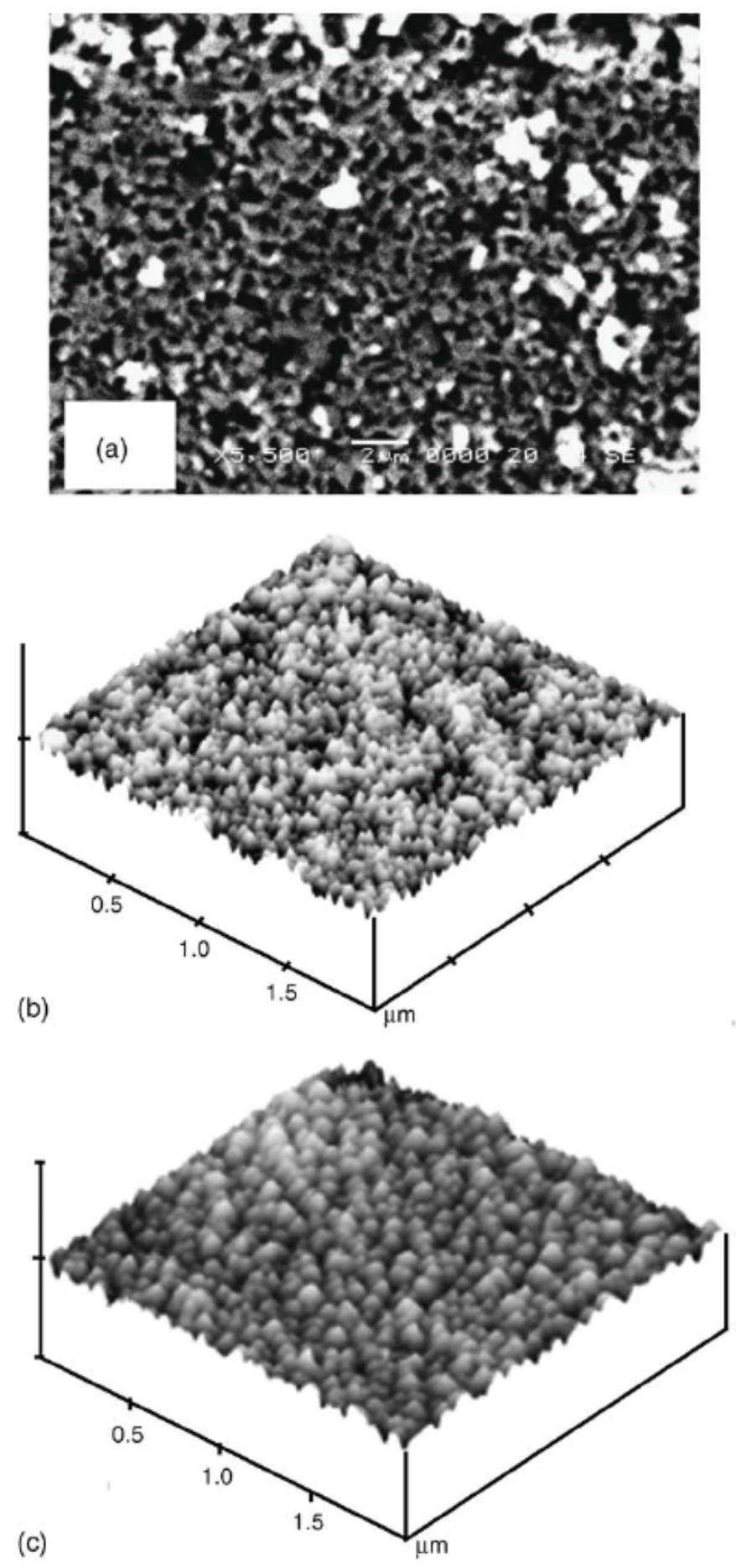

Fig. 2. The (a) SEM image of ZnMnO bulk, and AFM images of as-grown $\mathrm{ZnMnO}$ films grown at the substrate temperature of (b) $500{ }^{\circ} \mathrm{C}$ and (c) $600{ }^{\circ} \mathrm{C}$.

per primitive cell where all the atoms occupy $C_{3 v}$ sites. Eight sets of zone center optical phonons [20], [21] and [22], $2 \mathrm{~A}_{1}+2 \mathrm{E}_{2}+2 \mathrm{E}_{1}+2 \mathrm{~B}_{1}$, are predicted according to the group theory analysis. The $\mathrm{A}_{1}$ and 


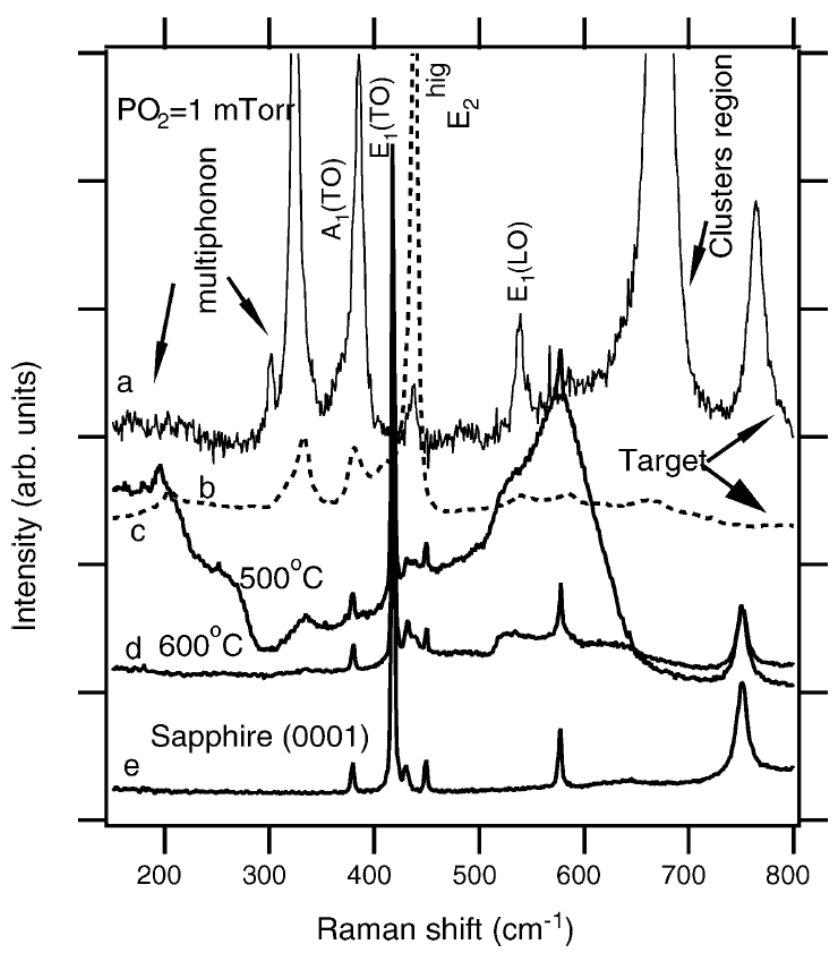

Fig. 3. Raman spectra of $\mathrm{ZnMnO}$ (a) bulk in the cluster region using $11 \mathrm{~mW}$ laser power, (b) in the normal region using $1.1 \mathrm{~mW}$ laser power, (c) film prepared at $T_{\mathrm{s}}=500{ }^{\circ} \mathrm{C}$, (d) film prepared at $T_{\mathrm{s}}=600^{\circ} \mathrm{C}$, and (e) of sapphire substrate.

$\mathrm{E}_{1}$ modes are polar and split into transverse optical (TO) and longitudinal optical (LO) phonons, and $\mathrm{E}_{2}$ mode consists of two modes of low and high frequency phonons. On the other hand, the $\mathrm{B}_{1}$ modes are not Raman active. To avoid sample photo transformation Raman spectra in the cluster region were recorded using low excitation power $(1.1 \mathrm{~mW})$. All normal region spectra in both bulk and films were recorded with $11 \mathrm{~mW}$ of power. We note that the beam spot size for the spectra at both normal and cluster regions was limited to only $<2 \mu \mathrm{m}$. The normal and the cluster regions in bulk are clearly distinguishable by the microscope attached to Raman spectrometer. It is noted that giant clusters of $1 \mu \mathrm{m}$ to several $\mu \mathrm{m}$ are seen in scanning electron microscopes. The cluster regions were very bright compared to the normal regions. In the normal region, the most intense peak at $437 \mathrm{~cm}^{-1}$ corresponds to the vibrational mode of $E_{2}^{\text {high }}$, and it is a typical Raman peak of $\mathrm{ZnO}$ bulk. The additional low intensity peaks observed in Fig. 3 are assigned to their respective modes. The modes at 203, 333 and 664, and above $1000 \mathrm{~cm}^{-1}$ are due to the multi-phonon scattering process. The $\mathrm{E}_{2}$ phonon mode centered around $437 \mathrm{~cm}^{-1}$ is obviously a good choice in order to understand the stress-induced phenomena in wurzite $\mathrm{ZnO}$. An increase in the $\mathrm{E}_{2}$ phonon frequency is generally ascribed to compressive stress, where as a decrease is caused by the tensile stress. However, the $\mathrm{E}_{2}$ phonon frequency observed at $437 \mathrm{~cm}^{-1}$ did not show any significant change in the Raman shift. In addition, we did not observe any extra peaks related to $\mathrm{Mn}$, suggesting that $\mathrm{Mn}$ is incorporated into $\mathrm{Zn}$. The most remarkable feature in Raman spectra is the improvement in the crystalline quality with increasing $T_{\mathrm{s}}$. This is clearly seen from the comparison of the spectrum (c) and (d), in which the $E_{1}(\mathrm{LO})$ mode in (d) becomes very broad.

In addition, the spectra in the cluster region of the target are significantly different compared to the spectra in the normal region. Surprisingly, the most intense $E_{2}$ phonon frequency at $437 \mathrm{~cm}^{-1}$ as discussed earlier disappeared completely. Especially, in the higher frequency region, two remarkable changes happened: (1) two new peaks emerged at about 675 and $765 \mathrm{~cm}^{-1}$, and (2) the multiphonon contribution observed in $\mathrm{ZnO}$ and for $\mathrm{ZnMnO}$ samples at normal spot completely disappeared. The Raman spectra of $\mathrm{MnO}_{2}$ show a relatively sharp peak at $\sim 765 \mathrm{~cm}^{-1}$ ( $v_{6}$ vibrational mode) ${ }^{18}$ indicative of a well-developed rutile-type $\mathrm{MnO}_{2}$ structure with an interstitial space consisting of narrow $1 \mathrm{D}$ channels. It is generally characterized by the presence of one sharp peak at $665 \mathrm{~cm}^{-1}$ along with four other bands at $319,377,486$ and $750 \mathrm{~cm}^{-1}$, those correspond to the skeletal vibrations. The bands at lower frequency region, such as 319,377 and $486 \mathrm{~cm}^{-1}$ in $\mathrm{MnO}_{2}$ overlap with those of $\mathrm{ZnO}$ and could not be clearly resolved. The main contributions are attributed to the stretching mode of the $\mathrm{Mn}-\mathrm{O}$ band in $\mathrm{MnO}_{6}$ octahedra at higher frequency and to the deformation modes of the metal oxygen chain of $\mathrm{Mn}-\mathrm{O}-\mathrm{Mn}$ in the $\mathrm{MnO}_{2}$ octahedra lattice at lower frequencies. However, the observation of giant clusters of $\mathrm{MnO}_{2}$ in $\mathrm{ZnO}$ matrix is complex and there are possibilities that some of these bands are diluted or totally masked depending on the cluster size, configuration and distribution.

The temperature dependence of the EPR spectra is shown in Fig. 4 for the target. The nature of EPR spectra did not show any significant change of slope for $T=77,240$ and $300 \mathrm{~K}$ in the spectral characteristics. However, both slope and the nature 


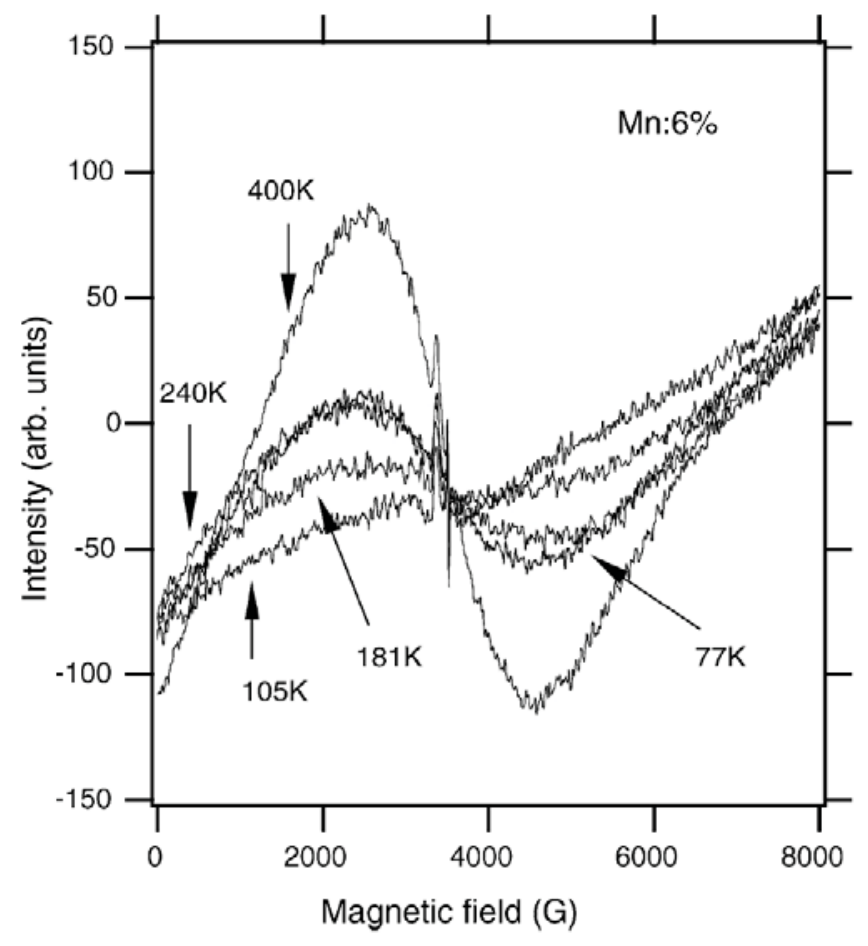

Fig. 4. Paramagnetic resonance spectra of 6 at. $\%$ Mn doping annealed at $500{ }^{\circ} \mathrm{C}$ for $12 \mathrm{~h}$ are shown for different temperatures.

of the EPR curves changes for $T=105$ and $181 \mathrm{~K}$. Surprisingly, the EPR spectra show a prominent paramagnetic behavior at $400 \mathrm{~K}$. This is a contrasting behavior to the generally observed EPR signal for paramagnetic samples where temperature is varied. We would expect a diminished EPR signal at higher temperatures. Although the clusters are inhomogeneous and contribute to the paramagnetic signals observed in our experiments, the anomalous temperature dependence of EPR signal in $\mathrm{ZnMnO}$ could not be explained and needs further studies. However, EPR results clearly suggest that no ferromagnetism is present in $\mathrm{ZnMnO}$ bulk material. The EPR measurements were measured on the film synthesized from the same target. However, EPR did not show any significant signal, probably limited by the sensitivity of the instrument.

In Fig. 4(a), we present the magnetic field dependence of the magnetization of $\mathrm{ZnMnO}$ target and films at $300 \mathrm{~K}$. The bulk target shows pronounced paramagnetic behavior. Fig. 4(b) shows the magnetic field dependence of magnetization curves of films at $300 \mathrm{~K}$. The film grown at $T_{\mathrm{s}}=500{ }^{\circ} \mathrm{C}$ exhibits a pronounced ferromagnetic behavior. The field at which the maximum in magnetization, $H_{\mathrm{m}}$ (low field to high field) is achieved decreases from
$980 \mathrm{G}$ at $5 \mathrm{~K}$ to $780 \mathrm{G}$ at $300 \mathrm{~K}$. The inset in Fig. 4(b) shows the temperature dependence of fieldcooled magnetization on the above film in an applied magnetic field of $100 \mathrm{G}$. The curve clearly illustrates that the Curie temperature is above $350 \mathrm{~K}$. The rapid rise of magnetization below $100 \mathrm{~K}$ may be attributed due to the presence of small Mn clusters, which become dominating factor for enhanced paramagnetism. However, the room temperature ferromagnetic hysteresis shrinks with increasing $T_{\mathrm{s}}$ (for $T_{\mathrm{s}}=600^{\circ} \mathrm{C}$ ), illustrating probably a dominant competition between ferromagnetic and anti-ferromagnetic states (Fig. 5).

In conclusion, we have demonstrated that the bulk material synthesized at $500{ }^{\circ} \mathrm{C}$ containing 6 at. $\%$ of
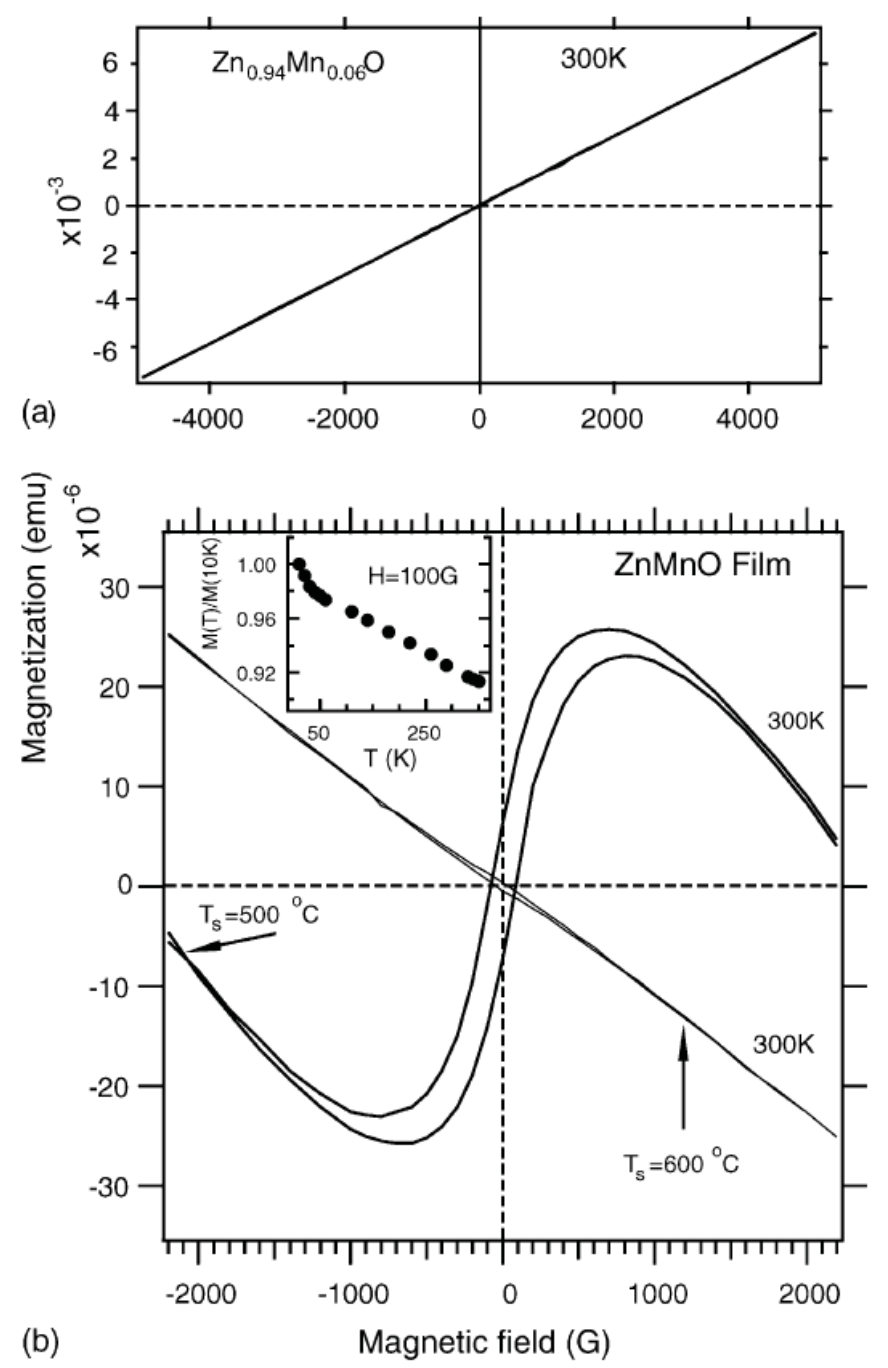

Fig. 5. The magnetization hysteresis loops of (a) ZnMnO bulk at $300 \mathrm{~K}$, (b) films for two growth temperatures. The inset in (b) shows the temperature dependence of field-cooled magnetization of film grown at a substrate temperature of $500{ }^{\circ} \mathrm{C}$. 
$\mathrm{Mn}$ in $\mathrm{ZnMnO}$ displays paramagnetic behavior due to the presence of large Mn-related clusters. However, the epitaxial $\mathrm{ZnMnO}$ films grown by a pulsedlaser deposition technique using the same target shows pronounced ferromagnetism at room temperature when synthesized at a substrate temperature of $500{ }^{\circ} \mathrm{C}$. The ferromagnetic properties become very week with increasing substrate temperature although the crystalline quality of the film improves. This contrasting behavior indicates that the $\mathrm{Mn}$ clustering, which is responsible for paramagnetic behavior, occurs at higher substrate temperature.

\section{Acknowledgements}

This work is supported by the National Aeronautics and Space Administration (NASA) and University Research Center (URC) cooperative agreement NCC-3-1035 and National Science Foundation (NSF) for Center for Research Excellence in Science and Technology (CREST) grant HRD-9805059. One of the authors (RRR) acknowledges the support from faculty research program provided by NASA. Research at the University of Nebraska is supported by NSF-MRSEC, ONR, and CMRA. Authors are thankful to A. Wilkerson for experimental help.

\section{References}

[1] (a) H. Ohno, Science 281 (1998), p. 951. (b) J. K. Furdyna, J. Appl. Phys. 64 (1988), pp. R29-R64.

[2] B. Beschoten, P.A. Crowell, I. Malajovich, D.D. Awschalom, F. Matsukura, A. Shen and H. Ohno, Phys. Rev. Lett. 83 (1999), p. 3073.

[3] I. Malajovich, J.J. Berry, N. Samarth and D.D. Awschalom, Nature 411 (2001), p. 770.

[4] M.L. Reed, N.A. El-Masry, H.H. Stadelmaier, M.K. Ritums, M.J. Reed, C.A. Parker, J.C. Roberts and S.M. Bedair, Appl. Phys. Lett. 79 (2001), p. 3473.

[5] S.J. Pearton, C.R. Abernathy, M.E. Overberg, G. Thaler, D.P. Norton, N. Theodoropoulou, A.F. Hebard, Y.D. Park, F. Ren, J. Kim and L.A. Boatner, J. Appl. Phys. 93 (2003), p. 1.
[6] M. Linnarsson, E. Janzén, B. Monemar, M. Kleverman and A. Thilderkvist, Phys. Rev. B 55 (1997), p. 6938.

[7] S.J. Pearton, Y.W. Heo, M. Ivill, D.P. Norton and T. Steiner, Semicond. Sci. Technol. 19 (2004), p. 59.

[8] T. Dietl, H. Ohno, F. Matsukura, J. Cibert and D. Ferrand, Science 287 (2000), p. 1019.

[9] M.E. Overberg, C.R. Abernathy, S.J. Pearton, N.A. Theodoropoulou, K.T. McCarthy and F. Hebard, Appl. Phys. Lett. 79 (2001), p. 1312.

[10] S.W. Jung, S.-J. An, G.-C. Yi, C.U. Jung, S. Lee and S. Cho, Appl. Phys. Lett. 80 (2002), p. 4561.

[11] D.P. Nort, S.J. Pearton, A.F. Hebard, N. Theodoropoulou, L.A. Boatner and R.G. Wilson, Appl. Phys. Lett. 82 (2003), p. 239.

[12] V.A.L. Roy, A.B. Djurisic, H. Liu, X.X. Zhang, Y.H. Leung, M.H. Xie, J. Gao, H.F. Liu and C. Surya, Appl. Phys. Lett. 84 (2004), p. 756.

[13] Y.W. Heo, M.P. Ivill, K. Ip, D.P. Nort, S.J. Pearton, J.G. Kelly, R. Rairigh, A.F. Hebard and T. Steiner, Appl. Phys. Lett. 84 (2004), p. 2292.

[14] X.M. Cheng and C.L. Chien, J. Appl. Phys. 93 (2003), p. 7876.

[15] T. Fukumura, Z. Jin, M. Kawasaki, T. Shono, T. Hasegawa and Koinuma, Appl. Phys. Lett. 78 (2001), p. 958.

[16] S.W. Yoon, S.-B. Cho, S.C. We, S. Yoon, B.J. Shul, K.K. Song and Y.J. Shin, J. Appl. Phys. 93 (2003), p. 7879.

[17] P. Sharma, A. Gupta, K.V. Rao, F.J. Owens, R. Verma, R. Ahuja, J.M.O. Guillen, B. Johansson and G.A. Gehring, Nat. Mater. 2 (2003), p. 673.

[18] A. Kaschner, U. Haboeck, M. Strassburg, G. Kaczmarczzyk, A. Hoffmann, C. Thomsen, A. Zeuner, H.R. Alves, D.M. Hofmann and B.K. Meyer, Appl. Phys. Lett. 80 (2002), p. 1909.

[19] D.C. Kundaliya, S.B. Ogale, S.E. Lofland, S. Dhar, C.J. Metting, S.R. Shinde, Z. Ma, B. Varughese, K.V. Ramanujachary, L. Salamanca-Riba and T. Venkatesan, Nat. Mater. 3 (2004), p. 709.

[20] T.C. Damen, S.P.S. Porto and B. Tell, Phys. Rev. 142 (1966), p. 570.

[21] F. Decremps, J.P. Porres, A.M. Saitta, J.C. Chervin and A. Polain, Phys. Rev. 65 (2002), p. 092101.

[22] C.M. Julien, M. Massot and C. Poinsignon, Spectrachem. Acta 60 (2004), p. 689. 